\title{
The BISMiS 2011 special issue on prokaryotic systematics, a vital discipline entering a period of transition
}

\author{
Iain C. Sutcliffe • Martha E. Trujillo • \\ Michael Goodfellow
}

Received: 3 November 2011/Accepted: 4 November 2011/Published online: 12 November 2011

(C) Springer Science+Business Media B.V. 2011

This Special Edition of Antonie van Leeuwenhoek contains a series of invited Perspective papers based on contributions made at the Inaugural Meeting of Bergey's International Society for Microbial Systematics, held in Beijing, China (19th-23rd May 2011). The 'BISMiS' conference was an outstanding success, drawing together over 370 delegates for a meeting where the excellence of the science was well matched by the splendid hospitality and efficient organisation by the local organising committee. We thank Guoping Zhao, Li Huang, Zixin Deng, Lixin Zhang and their colleagues, notably Liz Ashcroft, for their support and hard work in ensuring the meeting was such a success. Likewise, the support of the Bergey's Manual Trust was much appreciated.

One of the major themes to emerge from the conference was that microbial systematics remains a fundamentally important discipline albeit one at an

I. C. Sutcliffe ( $\square)$

School of Life Sciences, Northumbria University,

Newcastle Upon Tyne NE1 8ST, UK

e-mail: iain.sutcliffe@northumbria.ac.uk

M. E. Trujillo

Departamento de Microbiología y Genética,

Campus Miguel de Unamuno,

Universidad de Salamanca,

37007 Salamanca, Spain

M. Goodfellow

School of Biology, University of Newcastle,

Newcastle Upon Tyne NE1 7RU, UK important stage of development. We are grateful to Peter Kämpfer for an erudite overview on the current 'state of the art' and for spelling out the achievements of the past few decades. These achievements have been many, with significant growth in the numbers of published descriptions of microbial taxa. Nevertheless, significant challenges remain and these are addressed in the other contributions to this Special Issue. Not least among these is how to respond to our improved understanding of the vast diversity of the microbial world, a challenge elegantly described by Jim Staley in an influential article in the BISMiS bulletin as "the fourth goal of microbial taxonomy" (Staley 2010). Secondly, there is the challenge of embracing the technological drive and impact of the enormous and increasing mountains of sequence data that are being generated though microbial genome sequencing and metagenomic analyses. Addressing these unavoidable (but not insurmountable) challenges will be a defining feature of systematics in the next decade and should energise the next generation of microbial systematists. It was encouraging that so many young scientists contributed to the success of the Inaugural BISMiS meeting.

The challenge of embracing data derived from the application of new technologies has always been at the heart of systematics. In the last century, one such challenge was the application and integration of computational biology into the taxonomic framework through the development of numerical taxonomy. It is with great sadness that we learnt recently of the death 
of Peter Sneath, a pioneer in this field. Peter recognised that phenetics represented an approach to genotype and phylogenetics before gene and protein sequences were readily available. It is therefore fitting that we dedicate this Special Issue to Peter in celebration of his groundbreaking achievements. We recommend to readers Peter's own autobiographical account of his career, which was published in the first issue of The Bulletin of Bergey's International Society for Microbial Systematics (Sneath 2010).

\section{References}

Sneath PHA (2010) Reflections on microbial systematics. Bulletin of BISMiS 1. http://www.bergeys.org/bismisbulletin toc.html

Staley JT (2010) Comprehending microbial diversity: the fourth goal of microbial taxonomy. Bulletin of BISMiS 1. http:// www.bergeys.org/bismisbulletintoc.html 